\title{
Risk factors of mortality and permanent neurologic injury in patients undergoing ascending aortic and arch repair
}

Martin Czerny, MD

Tatjana Fleck, MD

Daniel Zimpfer, MD

Martin Dworschak, MD

Wolfgang Hofmann, MD

Doris Hutschala, MD

Daniela Dunkler, MSc

Marek Ehrlich, MD

Ernst Wolner, MD

Martin Grabenwoger, MD
From the Department of Cardiothoracic Surgery, University of Vienna Medical School, Vienna, Austria.

Received for publication March 12, 2003; revisions requested April 1, 2003; revisions received May 6, 2003; accepted for publication June 4, 2003.

Address for reprints: Dr Czerny, Waehringer Guertel 18-20, A-1090 Vienna, Austria (E-mail: bypass@eunet.at).

J Thorac Cardiovasc Surg 2003;126: 1296-301

Copyright $\odot 2003$ by The American Association for Thoracic Surgery

$0022-5223 / 2003 \$ 30.00+0$

doi:10.1016/S0022-5223(03)01046-8
Objectives: To analyze outcome in elderly patients after surgical repair of the ascending aorta and the aortic arch as compared with their younger counterparts and to determine risk factors of mortality and permanent neurologic injury.

Patients and Methods: Between January 1995 and February 2003, a total of 369 patients underwent ascending aortic and arch repair. Indications for surgical intervention were acute type A dissections in $174(47 \%)$ patients $(<75$ years, $\mathrm{n}=147$; $\geq 75$ years, $\mathrm{n}=27$ ) and chronic atherosclerotic aneurysms in $195(53 \%)$ patients $(<75$ years, $n=168 ; \geq 75$ years, $n=27)$. Emergency surgery was performed in 167 (45\%) patients; 202 patients $(54.7 \%)$ underwent surgery requiring deep hypothermic circulatory arrest. Pre- and intraoperative factors were evaluated by means of stepwise logistic regression analysis to determine risk factors of mortality and permanent neurologic injury.

Results: Overall in-hospital mortality was $11.6 \%$. In-hospital mortality with regard to indication for surgical intervention was comparable in both age groups (type A dissection: $<75$ years, $15.6 \% ; \geq 75$ years, $18.5 \% ; P=.731$; chronic atherosclerotic aneurysm: $<75$ years, $7.7 \%$; $\geq 75$ years, $7.4 \% ; P=.933$ ). Permanent neurologic injury was observed in $5.0 \%$. Permanent neurologic injury with regard to surgical intervention was comparable in both age groups (type A dissection: $<75$ years, $8.8 \%$; $\geq 75$ years, $3.7 \% ; P=.359$; chronic atherosclerotic aneurysm: $<75$ years, $3.0 \%$; $\geq 75$ years, $3.7 \% ; P=.843$ ). Stepwise logistic regression analysis revealed preoperative hemodynamic instability (odds ratio $4.3 ; P=.000$ ), duration of cardiopulmonary bypass (odds ratio 2.1; $P=.001$ ), and permanent neurologic injury (odds ratio $1.7 ; P=.033$ ) but not age as independent predictors affecting mortality. Utilization of but not duration of deep hypothermic circulatory arrest was the only independent predictor of permanent neurologic injury (odds ratio 2.8; $P=$ $.019)$.

Conclusions: Age shows a trend toward a higher risk of mortality but does not predict a higher incidence of permanent neurologic injury after ascending aortic and arch repair. As utilization of deep hypothermic circulatory arrest remains the only independent predictor of permanent neurologic injury, alternative approaches to maintain cerebral perfusion during ascending aortic and arch repair are warranted. 


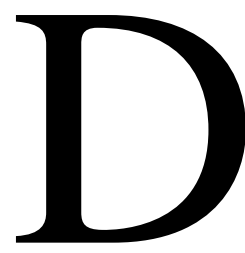

espite recent improvements in surgical technique and cerebral protection, surgical repair of the ascending aorta as well as the aortic arch still is an invasive procedure with a substantial rate of mortality and permanent neurologic injury. ${ }^{1-3}$ Longer life expectancy has led to an increased incidence of cardiovascular disease and consecutively to an increasing number of surgical interventions on the heart as well as the great vessels in the elderly. ${ }^{4}$ Drawn from the experience after coronary artery bypass grafting (CABG), age remains an independent predictor of early mortality and permanent neurologic injury. ${ }^{5,6}$ However, few series with diverging opinions are available with regard to mortality and permanent neurologic injury in elderly patients after surgical repair of the ascending aorta and the aortic arch. ${ }^{7-9}$

The aim of this study was to analyze outcome in elderly patients after surgical repair of the ascending aorta and the aortic arch as compared with their younger counterparts and to determine risk factors of mortality and permanent neurologic injury.

\section{Patients and Methods}

Between January 1995 and February 2003, a total of 443 consecutive patients underwent thoracic aortic operations at our institution. Of these, 369 patients underwent ascending aortic and arch repair. Indications for surgical intervention were acute type A dissections in 174 (47\%) patients ( $<75$ years, $\mathrm{n}=147$; $\geq 75$ years, $\mathrm{n}=27)$ and chronic atherosclerotic (degenerative) aneurysms in $195(53 \%)$ patients $(<75$ years, $\mathrm{n}=168 ; \geq 75$ years, $\mathrm{n}=27)$. Patients with chronic aortic dissections were not observed in the time frame of this analysis. No patients were refused surgery due to advanced age or comorbidities. Emergency surgery was performed in 167 (45\%) patients. In patients undergoing surgery for acute type A dissection, merely 4 had new neurological symptoms before surgery. End-organ malperfusion, presenting as newly developed renal insufficiency, was observed in 2 patients. Twelve patients suffered from histologically proven Marfan's syndrome. Patient demographics are shown in Table 1.

\section{Anesthesia and Surgical Procedure}

Midazolam in 1-mg increments was administered intravenously as needed for sedation during placement of monitors and invasive catheters. All patients received a standard general anesthesia with midazolam, etomidate, fentanyl, and pancuronium. Transesophageal echocardiography probe was placed after anesthetic induction in all patients. The transesophageal echocardiography views used to assess regional wall motion abnormalities included the transesophageal 4-chamber and 2-chamber views and the transgastric short-axis and long-axis views.

A median sternotomy approach was used in all cases. After systemic heparinization, cardiopulmonary bypass (CPB) was instituted. In all 174 patients with type A dissections, the femoral artery was routinely cannulated for arterial return. The ascending aorta or the concavity of the aortic arch was used as cannulation sites in 132 patients. In 54 patients with chronic atherosclerotic aneurysms extending into the aortic arch, the femoral artery was chosen. The right axillary artery was used in only 9 patients to date for arterial return. These 9 patients underwent surgery due to chronic atherosclerotic aneurysms. A venous 2-stage cannula was placed through the right heart ear into in the right atrium or a long venous cannula was inserted into the right atrium via the right femoral vein. The left side of the heart was vented either through the superior pulmonary vein or through the apex of the left ventricle according to the individual surgeon.

The CPB circuit consisted of a hollow-fiber oxygenator (Bard HF 5701, C.R. Bard Inc, Havorhill, Mass) primed with Ringer's lactate $2000 \mathrm{~mL}$, mannitol $20 \mathrm{~g}$, heparin $8000 \mathrm{IU}$ (Immuno, Vienna, Austria), and aprotinin 1,000,000 IU (Trasylol Bayer, Leverkusen, Germany) as well as a roller pump (Stöckert Instruments, Munich, Germany). Flow during CPB was maintained at $2.5 \mathrm{~L} / \mathrm{min} / \mathrm{m}^{2}$. Myocardial preservation during aortic crossclamping was achieved by $4^{\circ} \mathrm{C}$ cold intermittent ante- and retrograde blood cardioplegia. Blood cardioplegia in a 4:1 ratio was used. Hematocrit level was kept higher than $20 \%$ with donor blood if necessary. Acid-base balance was maintained with an alpha-stat strategy. Filtration was used in selected cases where fluid or electrolyte balance could not be maintained conventionally. During cooling, concomitant procedures on the heart were performed. After core cooling to $18^{\circ} \mathrm{C}$ was achieved (measures taken within the bladder), systemic circulation was arrested, and the diseased aorta was opened. To increase ischemic tolerance of the brain, the patient's head was packed in ice bags. Methylprednisolone $(1 \mathrm{~g})$ was given immediately before circulatory arrest.

The decision to use retrograde cerebral perfusion (RCP) was subjected to the individual surgeon. RCP was prevailingly used in the initial period of this analysis. RCP was begun through the superior caval vein with a perfusion temperature of $18^{\circ} \mathrm{C}$. Therefore, the vessel was circumferentially dissected, cannulated, snared, and perfused by a second line, connected to the arterial line of the CPB circuit. RCP was started at a rate of $5 \mathrm{~mL} / \mathrm{min} / \mathrm{kg}$. Flows were adjusted to maintain central venous pressures between 20 and $25 \mathrm{~mm} \mathrm{Hg}$. Tools of neuromonitoring included a right arterial pressure line in all cases, as well as regional oxygen saturation in the bilateral frontal lobes via near-infrared spectroscopy.

For aortic arch repair, gelatin-sealed, shaped, woven polyester grafts (Vascutek Ltd, Scotland, UK) were used, which had a premanufactured 8-mm Dacron graft sutured end-to-side into the prosthesis. The anastomoses were performed with running 4-0 Prolene sutures and reinforced with a 3-mm-wide Teflon felt, which was incorporated into the anastomosis. Thereafter, if used, $\mathrm{RCP}$ was discontinued and the arterial side graft of the CPB circuit was connected to the 8-mm Dacron side graft of the prosthesis. In the case of proximal arch replacement, the aortic graft was clamped proximal to the junction of the side graft, and antegrade hypothermic perfusion was initiated. Patients were rewarmed while the proximal anastomosis was performed

An overview of the extent of aortic replacement is given in Table 2. After weaning from CPB, mean arterial pressure was maintained above $60 \mathrm{~mm} \mathrm{Hg}$ with fluid loading and appropriate vasoactive drugs. Treatment in the intensive care unit (ICU) was defined by institutional standards. 
TABLE 1. Patient demographics and clinical characteristics

\begin{tabular}{|c|c|c|c|c|}
\hline & \multicolumn{2}{|c|}{ Type A dissection } & \multicolumn{2}{|c|}{ Atherosclerotic aneurysm } \\
\hline & $<75$ years & $\geq 75$ years & $<75$ years & $\geq 75$ years \\
\hline$n$ & 147 & 27 & 168 & 27 \\
\hline Mean age (years) & $53 \pm 12$ & $78 \pm 3$ & $56 \pm 12$ & $78 \pm 2$ \\
\hline Sex (\% male) & 66 & 52 & 68 & 33 \\
\hline Emergency surgery (\%) & 91.8 & 88.9 & 4.2 & 3.7 \\
\hline Preoperative hemodynamic instability (\%) & 14.4 & 18.5 & 0.0 & 0.0 \\
\hline Previous heart surgery $(\%)$ & 6.1 & 3.7 & 15.1 & 0.0 \\
\hline
\end{tabular}

TABLE 2. Extent of aortic replacement and concomitant procedures

\begin{tabular}{|c|c|c|c|c|}
\hline & \multicolumn{2}{|c|}{ Type A dissection } & \multicolumn{2}{|c|}{ Atherosclerotic aneurysm } \\
\hline & $<75$ years & $\geq 75$ years & $<75$ years & $\geq 75$ years \\
\hline Ascending aorta (n) & 14 & 2 & 92 & 20 \\
\hline Ascending aorta and hemiarch (n) & 94 & 20 & 21 & 6 \\
\hline Total arch replacements $(\mathrm{n})$ & 15 & & 6 & \\
\hline Elephant trunk procedures (n) & & & 2 & \\
\hline Composite graft $(\mathrm{n})$ & 23 & 2 & 47 & 1 \\
\hline Other $(\mathrm{n})$ & 1 & 3 & 0 & 0 \\
\hline
\end{tabular}

\section{Definition of Clinical Parameters}

Mortality was defined as in-hospital death. Transient neurologic injury was defined as the occurrence of postoperative confusion, agitation, delirium, or prolonged obtundation without morphological correlates. Permanent neurologic injury was defined as new onset of focal injury (stroke) or global dysfunction (coma) after surgical repair with and without morphological correlates in cranial computed tomography. All patients with overt neurological or neurocognitive deficits after surgery were examined by a neurologist. As a consequence, further investigations such as cranial computed tomography or magnetic resonance imaging were obtained. Emergency surgery was defined as need for surgical intervention before the next regular working day. Preoperative hemodynamic instability was defined as need for inotropic or vasopressor support to maintain a mean arterial pressure of at least $60 \mathrm{~mm} \mathrm{Hg}$.

\section{Statistical Analysis}

Continuous variables are expressed as means \pm SD. Categorical variables are expressed as percentages. After testing for normality of distribution, continuous variables were compared using Student $t$ test. Categorical variables were compared using chi-square test or Fisher exact test as appropriate. To determine risk factors of mortality and permanent neurologic injury, a stepwise logistic regression analysis was performed. Pre- and intraoperative variables tested are listed in the appendix. The entrance level for multivariate analysis was a $P$ value of below .05 within univariate analysis. The analysis for permanent neurologic injury was carried out separately in all patients surviving surgery. Statistical analysis was performed with SPSS 11.0 statistical software (SPSS, Inc, Chicago, Ill).

\section{Results}

\section{Cardiopulmonary Bypass Data}

Mean CPB time was $169 \pm 57$ minutes (range 41-563 minutes) (type A dissection: $<75$ years, $190 \pm 55$ minutes; $\geq 75$ years, $199 \pm 51$ minutes; $P=.452$; chronic atherosclerotic aneurysm: $<75$ years, $160 \pm 67$ minutes; $\geq 75$ years, $127 \pm 57$ minutes, $P=.017)$ and the mean myocardial ischemic time was $97 \pm 39$ minutes (range 10-285 minutes) (type A dissection: $<75$ years, $104 \pm 41$ minutes; $\geq 75$ years, $105 \pm 44$ minutes; $P=.930$; chronic atherosclerotic aneurysm: $<75$ years, $106 \pm 41$ minutes; $\geq 75$ years, $75 \pm 33$ minutes; $P=.000)$. Mean deep hypothermic circulatory arrest (DHCA) time was $31 \pm 16$ minutes (type A dissection: $<75$ years, $32 \pm 16$ minutes; $\geq 75$ years, $30 \pm$ 11 minutes; $P=.487$; chronic atherosclerotic aneurysm: $<75$ years, $30 \pm 15$ minutes; $\geq 75$ years, $25 \pm 14$ minutes; $P=.335)$. The distribution of patients on the basis of DHCA time is shown in Figure 1.

\section{In-Hospital Mortality}

Overall in-hospital mortality was $11.6 \%$. In-hospital mortality with regard to indication for surgical intervention was comparable in both age groups (type A dissection: $<75$ years, $15.6 \%$; $\geq 75$ years, $18.5 \% ; P=.731$; chronic atherosclerotic aneurysm: $<75$ years, $7.7 \%$; $\geq 75$ years, $7.4 \% ; P$ $=.933$ ). In-hospital mortality was $7.6 \%$ in patients undergoing elective and $16.9 \%$ in patients undergoing emergency surgery $(P=.006)$. Causes of death were multiorgan failure in $40 \%$, low cardiac output in $25 \%$, cerebral bleeding or ischemia with concomitant brain stem infarction in $12.5 \%$, 


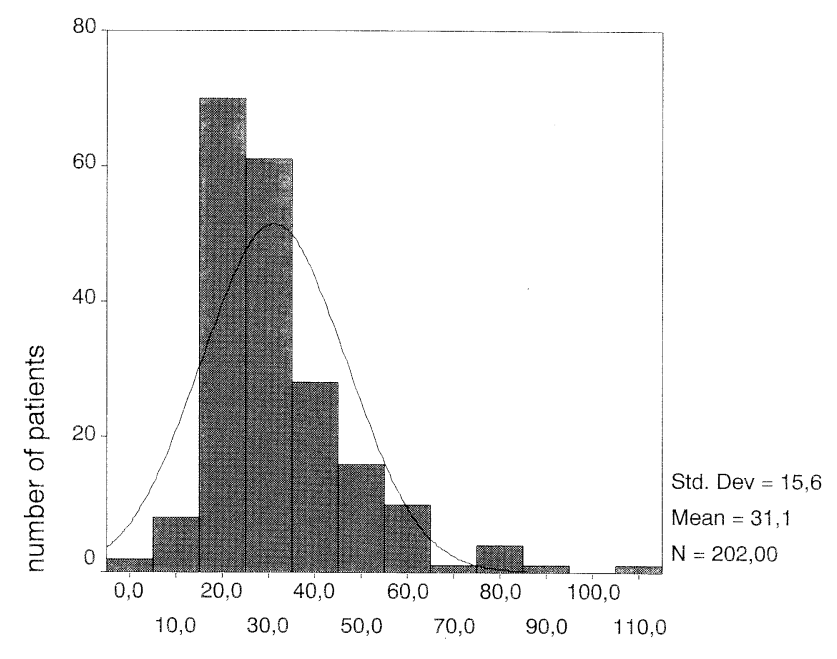

DHCA time (min)

Figure 1. Distribution of patients with regard to DHCA time.

bleeding in 10\%, sepsis in 10\%, and acute respiratory distress syndrome in $2.5 \%$.

\section{Transient and Permanent Neurologic Injury}

Transient neurologic injury was detected in $15.7 \%$, irrespective of indication and age. Permanent neurologic injury was observed in $5.0 \%$. Permanent neurologic injury with regard to surgical intervention was comparable in both age groups (type A dissection: $<75$ years, $8.8 \%$; $\geq 75$ years, $3.7 \% ; P=$ .359; chronic atherosclerotic aneurysm: $<75$ years, $3.0 \%$; $\geq 75$ years, $3.7 \% ; P=.843$ ), respectively.

\section{Univariate Analysis with Regard to Mortality and Permanent Neurologic Injury}

Univariate regression analysis revealed age $(P=.045)$, indication for surgery (type A dissection) $(P=.031)$, emergency procedures $(P=.012)$, preoperative hemodynamic instability $(P=.000)$, duration of DHCA $(P=.003)$, retrograde cerebroperfusion $(P=.008)$, duration of CPB $(P$ $=.000)$, and ICU stay $(P=.001)$, as well as permanent neurologic injury $(P=.001)$ to be univariate predictors of mortality. (See Table 3.)

Univariate predictors of permanent neurologic injury were indication for surgery (type A dissection) $(P=.048)$, emergency procedures $(P=.033)$, preoperative hemodynamic instability $(P=.017)$, utilization of DHCA $(P=$ $.000)$, duration of DHCA $(P=.043)$, and retrograde cerebroperfusion $(P=.011)$, as well as duration of CPB $(P=$ .040; odds ratio $[\mathrm{OR}] / \mathrm{min}$ CPB time 1.035). Age did not predict permanent neurologic injury $(P=.119)$. (See Table 4.)
TABLE 3. Univariate and multivariate analysis with regard to mortality

\begin{tabular}{lccc}
\hline & $\begin{array}{c}\text { Univariate } \\
\text { analysis }\end{array}$ & $\begin{array}{c}\text { Multivariate } \\
\text { analysis }\end{array}$ & OR \\
\hline Age & .045 & & \\
$\begin{array}{l}\text { Indication for surgery (type A } \\
\quad \text { dissection) }\end{array}$ & .031 & & \\
$\begin{array}{l}\text { Emergency surgery } \\
\text { Preoperative hemodynamic }\end{array}$ & .012 & & \\
$\quad$ instability & .000 & .000 & 4.3 \\
$\begin{array}{l}\text { Duration of DHCA } \\
\text { Retrograde cerebroperfusion }\end{array}$ & .003 & & \\
Duration of CPB & .008 & & \\
ICU stay & .000 & .001 & 2.1 \\
Permanent neurologic injury & .001 & & \\
\hline
\end{tabular}

$O R$, Odds ratio; $D H C A$, deep hypothermic circulatory arrest; $C P B$, cardiopulmonary bypass; $I C U$, intensive care unit.

TABLE 4. Univariate and multivariate analysis with regard to permanent neurologic injury

\begin{tabular}{lccc}
\hline & \multicolumn{3}{c}{ Univariate } \\
& Multivariate \\
& analysis & analysis & OR \\
\hline Age & .119 & & \\
Indication for surgery (type A dissection) & .048 & & \\
Emergency surgery & .033 & & \\
Preoperative hemodynamic instability & .017 & & \\
Utilization of DHCA & .000 & .019 & 2.8 \\
Duration of DHCA & .043 & & \\
Retrograde cerebroperfusion & .011 & & \\
Duration of CPB & .040 & & \\
\hline
\end{tabular}

$O R$, Odds ratio; DHCA, deep hypothermic circulatory arrest; $C P B$, cardiopulmonary bypass.

\section{Multivariate Analysis with Regard to Mortality and Permanent Neurologic Injury}

Stepwise logistic regression analysis revealed preoperative hemodynamic instability (OR 4.3; $P=.000$ ), duration of cardiopulmonary bypass (OR $2.1 ; P=.001$ ), and permanent neurologic injury (OR 1.7; $P=.033$ ) but not age (OR $1.0 ; P=.078)$ as independent predictors affecting mortality. Utilization but not duration of DHCA was the only independent predictor of permanent neurologic injury (OR $2.8 ; P=.019$; see Tables 3 and 4 ).

\section{Discussion}

Age shows a trend toward a higher risk of mortality but does not predict a higher incidence of permanent neurologic injury after ascending aortic and arch repair. As utilization of DHCA remains the only independent predictor of permanent neurologic injury, alternative approaches to maintain cerebral perfusion during ascending aortic and arch repair are warranted.

Few data with diverging opinions are available with regard to mortality and permanent neurologic injury in

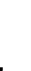


elderly patients after surgical repair of the ascending aorta and the aortic arch. ${ }^{7-9}$ Previous series concluded that aortic surgery with DHCA in octogenarians can be performed with an acceptable risk of mortality and permanent neurologic injury in an elective setting. In the acute setting outcome worsened dramatically in this series. ${ }^{7}$ Recent work supported that DHCA can be applied with an acceptably low early mortality in octogenarians, with the drawback of an increased incidence of postoperative permanent neurologic dysfunction. ${ }^{9}$ Finally, another group, due to their dismal results in octogenarians after surgical repair of acute type A dissections, reflected denying surgery to this particular high-risk subgroup of patients. ${ }^{8}$ However, these studies used DHCA as the prevailing adjunct to protect the brain. Alternative approaches were not routinely used.

Recently, RCP has been called into question as the procedure may not be effective to serve as metabolic adjunct to DHCA. ${ }^{10}$ However, antegrade cerebral perfusion (ACP) developed as a useful tool to protect the brain during arch repair and is gradually gaining extended clinical application. ${ }^{11,12}$ ACP is associated with improved cerebral recovery and furthermore can be used with moderate cooling, thereby avoiding side effects of conventional DHCA. ${ }^{13,14}$ In a recent investigation, reduced transient neurological deficit rates since the implementation of ACP could be observed. ${ }^{15}$ By using alternative cannulation sites such as the axillary artery, potential complications of accidental embolization during manipulation of the arch vessels may also be reduced. ${ }^{15}$

Overall in-hospital mortality was $11.6 \%$, thereby comparing favorably with other recent series. ${ }^{11,16}$ In multivariate regression analysis, preoperative hemodynamic instability, duration of extracorporeal circulation, and permanent neurologic injury turned out to be independent predictors of in-hospital mortality. This is in contrast with others. The series by Di Eusanio and colleagues ${ }^{11}$ revealed emergency surgery as well as a recent central neurologic event as independent predictors of in-hospital mortality. However, no definition of emergency surgery and central neurologic events was provided. In our series emergency surgery, defined as need for surgical intervention before the next regular working day, merely gained significance in univariate analysis. In our clinical experience, patients with hemodynamically stable, contained ruptures perform significantly better than patients with hemodynamic compromise. As multivariate regression analysis has shown, preoperative hemodynamic status has a more severe impact on in-hospital mortality than an emergency status underlying individual subjective definition criteria.

In line with others, duration of $\mathrm{CPB}$ and permanent neurologic injury were independent predictors of in-hospital mortality. ${ }^{16,17}$ Interestingly, age failed to obtain significance as an independent predictor of in-hospital mortality, al- though a trend toward significance could be observed. This in contrast with other studies. ${ }^{7-9,11,17}$ It is generally accepted that morbidity and mortality rise with increasing age and that the elderly are generally more frail and have a diminished physiologic reserve when compared with their younger counterparts. ${ }^{9,18}$ However, it seems likely that preoperative hemodynamic instability, often associated with rupture, per se has such a tremendous impact on outcome that age loses its significance in independently predicting a higher rate of in-hospital mortality.

Utilization but not duration of DHCA was the only independent predictor of permanent neurologic injury. This is an interesting finding as duration of DHCA is an independent predictor in the majority of published series. ${ }^{13,19-21}$ However, data exist supporting our findings. Findings from a recent clinical investigation indicated that even relatively short and clinically safe periods of DHCA are associated with a subclinical cerebral ischemic insult, despite temperature suppression of metabolism. ${ }^{10}$ In our series, duration of DHCA was rather short and only a small number of patients had DHCA times greater than 40 minutes. This finding may account for our low rate of permanent neurologic injury irrespective of indication and age and may attribute to the fact that duration of DHCA gained significance merely in univariate but not in multivariate analysis.

The fact that utilization of DHCA has a significant impact on the incidence of permanent neurologic injury prompted us to reconsider brain protection techniques during DHCA. Promising results in minimizing risk of permanent neurologic injury could already be obtained by application of selective antegrade cerebral perfusion..$^{11,12,16}$ Based on these results we modified our technique and implemented antegrade cerebral perfusion by routine cannulation of the right axillary artery and selective intubation of the left carotid artery during open arch repair.

We therefore conclude that age shows a trend toward a higher risk of mortality but does not predict a higher incidence of permanent neurologic injury after ascending aortic and arch repair. As utilization of DHCA remains the only independent predictor of permanent neurologic injury, alternative approaches to maintain cerebral perfusion during ascending aortic and arch repair are warranted.

\section{References}

1. Kazui T, Washiyama N, Muhammad BAH, Terada H, Yamashita K, Takinami M. Improved results of atherosclerotic arch aneurysm operations with a refined technique. J Thorac Cardiovasc Surg. 2001;121: 491-9.

2. Westaby S, Katsumata T. Proximal aortic perfusion for complex arch and descending aortic disease. J Thorac Cardiovasc Surg. 1998;115: $162-7$.

3. Kazui T, Yamashita K, Washiyama N, Terada H, Bashar AH, Suzuki $\mathrm{T}$, et al. Usefulness of antegrade cerebral perfusion during aortic arch operations. Ann Thorac Surg. 2002;74:S1806-9.

4. Statistical Abstract of the United States: 1991. 11th ed. Washington, DC: US Bureau of the Census; 1991. p. 81. 
5. Blackstone E, Lytle B. Competing risk after coronary bypass surgery: the influence of death on reintervention. J Thorac Cardiovasc Surg. 2000;119:1221-30.

6. Ricci M, Karamanoukian HL, Abraham R, et al. Stroke in octogenarians undergoing coronary artery surgery with and without cardiopulmonary bypass. Ann Thorac Surg. 2000;69:1471-5.

7. Hagl C, Galla JD, Spielvogel D, et al. Is aortic surgery using hypothermic circulatory arrest in octogenarians justifiable? Eur J Cardiothorac Surg. 2001;19:417-23.

8. Neri E, Toscano T, Massetti M, et al. Operation for acute type A aortic dissection in octogenarians: is it justified? J Thorac Cardiovasc Surg. 2001;121:259-67.

9. Liddicoat JR, Redmond JM, Vassileva CM, Baumgartner WA, Cameron DE. Hypothermic circulatory arrest in octogenarians: risk of stroke and mortality. Ann Thorac Surg. 2000;69:1048-52.

10. Bonser RS, Wong CH, Harrington D. Failure of retrograde cerebral perfusion to attenuate metabolic changes associated with hypothermic circulatory arrest. J Thorac Cardiovasc Surg. 2002;123:943-50.

11. Di Eusanio M, Schepens MAAM, Morshuis WJ, Di Bartolomeo R, Pierangeli A, Dossche KM. Antegrade selective cerebral perfusion during operations on the thoracic aorta: factors influencing survival and neurologic outcome in 413 patients. J Thorac Cardiovasc Surg. 2002;124:1080-6.

12. Bachet J, Guilmet D, Goudot B, et al. Antegrade cerebral perfusion with cold blood: a 13-year experience. Ann Thorac Surg. 1999;67: 1874-8.

13. Svensson LG, Crawford ES, Hess HR, et al. Deep hypothermia with circulatory arrest: determinants of stroke and early mortality in 656 patients. J Thorac Cardiovasc Surg. 1993;106:19-31.

14. Cooper WA, Duarte IG, Thourani VH, et al. Hypothermic circulatory arrest causes multisystem vascular endothelial dysfunction and apoptosis. Ann Thorac Surg. 2000;69:696-703.

15. Hagl C, Ergin AM, Galla JD, et al. Neurologic outcome after ascending aorta-aortic arch operations: effect of brain protection technique in high risk patients. J Thorac Cardiovasc Surg. 2001;121:1107-21.

16. Kazui T, Washijama N, Muhammad BAH, et al. Total arch replacement using aortic arch branched grafts with the aid of antegrade selective cerebral perfusion. Ann Thorac Surg. 2000;70:3-9.

17. Ueda Y, Okita Y, Aomi S, Koyonagi H, Takamoto S. Retrograde cerebral perfusion for aortic arch surgery: analysis of risk factors. Ann Thorac Surg. 1999;67:1879-82.

18. Bergsland J, Hasnain S, Lajos TZ, et al. Elimination of cardiopulmonary bypass: a prime goal in reoperative coronary bypass surgery. Eur J Cardiothorac Surg. 1998;14:59-63.

19. Ergin MA, Galla JD, Lansman SL, Quintana C, Bodian C, Griepp RB. Hypothermic circulatory arrest in operations on the thoracic aorta: determinants of operative mortality and neurologic outcome. J Thorac Cardiovasc Surg. 1994;107:788-99.

20. Ergin MA, Uysal S, Reich DL, et al. Temporary neurologic dysfunction after deep hypothermic circulatory arrest: a clinical marker of long-term functional deficit. Ann Thorac Surg. 1999;67:1887-90.

21. Ehrlich MP, Ergin MA, McCullough JN, et al. Predictors of adverse outcome and transient neurological dysfunction after ascending aorta/ hemiarch replacement. Ann Thorac Surg. 2000;69:1755-63.

\section{Appendix}

Preoperative and Intraoperative Variables Tested

Age

Sex

Preoperative renal insufficiency

Chronic obstructive lung disease

Coronary artery disease

Indication for surgery

Emergency surgery

Preoperative hemodynamic instability

Previous cardiac surgery

Extent of replacement

Concomitant procedures

Utilization of DHCA

Duration of DHCA

Retrograde cerebroperfusion

Duration of CPB

Duration of myocardial ischemia

ICU stay

Permanent neurologic injury 